\title{
DETERMINACIÓN DE LAS PROPIEDADES TÉRMICAS Y COMPOSICIONALES DE LA HARINA Y ALMIDÓN DE CHACHAFRUTO (Erytina Edulis Triana Ex Micheli)
}

\section{DETERMINATION OF COMPOSITIONAL AND THERMAL PROPERTIES OF FLOUR AND STARCH OF CHACHAFRUTO (Erytina Edulis Triana Ex Micheli)}

\author{
Erika N. Álzate Carvajal'1, Víctor Dumar Quintero Castaño², Juan Carlos Lucas Aguirre ${ }^{3}$
}

Recibido para publicación: Mayo 28 de 2013 - Aceptado para publicación: Diciembre 11 de 2013

\begin{abstract}
RESUMEN
Este trabajo presenta un estudio sobre las propiedades químicas, térmicas y estructurales de las harinas y almidones de chachafruto. Se realizó un análisis proximal tanto a la harina como al almidón de chachafruto (Erytrina Edulis Triana Ex Micheli) en las cuales se evaluaron parámetros como humedad, minerales, proteína, grasas, fibra y porcentaje de almidón. Las propiedades térmicas se determinaron con las técnicas de Calorimetría Diferencial de Barrido, Análisis Termogravimétrico y Análisis por Viscoamilografía Rápida y las estructurales se determinaron por Difracción de Rayos X y por Microscopia Electrónica de Barrido. El análisis proximal para la harina presentó: humedad $12,33 \%$, cenizas 1,55\%, proteína $18,5 \%$, extracto etéreo 2,50\%. Para el almidón: Humedad $12,60 \%$, cenizas $0,90 \%$, extracto etéreo $1,82 \%$ y proteína $0,8 \%$. Los gránulos de almidón presentaron formas esféricas y ovoides. Para la harina la temperatura de pérdida de humedad fue de $119,99^{\circ} \mathrm{C}$, la temperatura máxima de descomposición se presentó en los $272,5^{\circ} \mathrm{C}$ y finalmente el proceso termina en $581^{\circ} \mathrm{C}$. Para el almidón la descomposición del agua se estableció a $200,94^{\circ} \mathrm{C}$, la temperatura máxima de descomposición presentó un pico en $300^{\circ} \mathrm{C}$ y el proceso finalizó a $584,72^{\circ} \mathrm{C}$. Al realizar el análisis por DSC para la harina se encontró que las temperaturas características para el proceso de gelatinización son $\mathrm{TO}=62,06^{\circ} \mathrm{C}, \mathrm{TP}=70,98^{\circ} \mathrm{C}, \mathrm{TF}=78,62^{\circ} \mathrm{C}$ y para el almidón se obtuvo que $\mathrm{TO}=56,65^{\circ} \mathrm{C}, \mathrm{TP}=70,06 \%$, $\mathrm{TF}=85,12^{\circ} \mathrm{C}$.
\end{abstract}

Palabras clave: Chachafruto, harinas, almidones, procesos químicos, temperatura.

\begin{abstract}
This paper presents a study on the chemical, thermal and structural properties of chachafruto's flours and starches. A proximal analysis was performed both flour and starch of chachafruto (Erytrina Edulis Triana Ex Micheli) determining parameters such as moisture, minerals, protein, fat, fiber and starch percentage. The thermal properties were determined with the techniques of differential scanning calorimetry, thermogravimetric analysis and Rapid Viscoamilography Analysis and structural were determined by X-ray diffraction and scanning electronic microscopy. The proximal analysis for flour presented: moisture $12.33 \%$, ash $1.55 \%$,
\end{abstract}

\footnotetext{
${ }^{1 *}$ Ingeniera Agroindustrial. Universidad de la Gran Colombia, Armenia

${ }^{2}$ Químico, M.Sc. Docente programa de Ingeniería Industrial, Corporación Universitaria Empresarial Alexander Von Humboldt

${ }^{3}$ Ingeniero Agroindustrial, M.Sc. Universidad del Quindío
} 
$18.5 \%$ protein, ether extract $2.50 \%$. For starch: Moisture $12.60 \%, 0.90 \%$ ash, ether extract $1.82 \%$ and $0.8 \%$ protein. Starch granules spherical and ovoid forms submitted. The TGA for flour showed a temperature of moisture loss of $119.99^{\circ} \mathrm{C}$, the maximum temperature of decomposition was presented in the $272.5^{\circ} \mathrm{C}$ and finally the process ends at $581^{\circ} \mathrm{C}$. Starch granules presented spherical and ovoid forms. To the flour, the temperature of moisture loss was $119.99^{\circ} \mathrm{C}$, the maximum temperature of decomposition was presented in the $272.5^{\circ} \mathrm{C}$ and finally the process ends at $581^{\circ} \mathrm{C}$. For starch, the decomposition of water was established at $200.94^{\circ} \mathrm{C}$, the maximum temperature of decomposition showed a peak at $300^{\circ} \mathrm{C}$ and the process ended at $584.72^{\circ} \mathrm{C}$. When performing the DSC analysis for the flour was found that the characteristic temperatures for the gelatinization process are $\mathrm{TO}=62.06^{\circ} \mathrm{C}, \mathrm{TP}=70,98^{\circ} \mathrm{C}, \mathrm{TF}=78.62^{\circ} \mathrm{C}$ and for starch was obtained that $\mathrm{TO}=$ $56.65^{\circ} \mathrm{C}, \mathrm{TP}=70.06 \%, \mathrm{TF}=85.12^{\circ} \mathrm{C}$.

Key words: Chachafruto, Flour, Starch, Chemical processes, temperature

\section{INTRODUCCIÓN}

Para nutrir de manera adecuada a una población, debe haber en el país una suficiente cantidad y variedad de alimentos inocuos y de buena calidad. Por lo tanto, en la mayoría de los países que tienen bajos ingresos y déficit alimentario, una estrategia fundamental de política alimentaria es mejorar y aumentar la producción de los alimentos, campo pertinente para expertos en agricultura. Claramente, quienes toman decisiones en el sector agrícola necesitan tener conciencia sobre las necesidades nutricionales de la población y entender las implicaciones nutricionales de sus acciones (Latham 2002).

La mayoría de los alimentos en el mundo provienen de los cereales, el segundo gran conjunto de alimentos provienen de cosechas de raíces y el tercero de legumbres o leguminosas. En cifras redondas, el mundo produce aproximadamente 2000 millones de toneladas de cereales, 600 millones de toneladas de cosechas de raíces y 60 millones de toneladas de legumbres por año. Además, cada año en el mundo entero se producen aproximadamente 85 millones de toneladas de grasas y aceites y 180 millones de toneladas de azúcares. Los países en desarrollo producen más cantidad de todos estos artículos que los países industrializados. En contraste, los países industrializados producen más alimentos de origen animal, carne, leche y huevos que los países en desarrollo (Young y Pellet 1994).

En la última década, se han registrado adelantos verdaderamente notables que han influido en la producción alimentaria. La investigación agrícola ha desarrollado y ofrece nuevas variedades de los principales cereales: arroz, maíz y trigo. Estas nuevas variedades producen rendimientos más altos por hectárea que las variedades tradicionales. Algunos tienen un período más corto entre la siembra y la cosecha y algunos son relativamente resistentes a las plagas (Latham 2002 y Ruskin 1989).

Las proteínas, como los carbohidratos y las grasas, contienen carbono, hidrógeno y oxígeno, pero también contienen nitrógeno y a menudo azufre. Son muy importantes como sustancias nitrogenadas necesarias para el crecimiento y la reparación de los tejidos corporales. Las proteínas son el principal componente estructural de las células y tejidos y constituyen la mayor porción de sustancia de los músculos y órganos, sin incluir el agua corporal (Young and Pellet 1994).

Una de estas especies promisorias y que ha sido objeto de estudios por parte del Instituto 
de Investigación de Recursos Biológicos Alexander von Humboldt, es el chachafruto (Erythrina edulis Triana ex micheli), el cual por sus múltiples potencialidades es de gran importancia, desde el punto de vista de la conservación y seguridad agroalimentaria tanto para consumo humano como animal.

El chachafruto es una de las más versátiles especies de las Erythrina identificadas de la familia Fabácea, subfamilia papilionoidae; es una leguminosa multipropósito con un amplio espectro de usos, debido a su concentración de almidón, y según el reporte de algunos autores por su alto contenido de proteína (Jyothirmayi et al. 2006). Según Ruskin (1989) generalmente la población mundial y la industria demandan grandes cantidades de proteína y almidón, lo que ha estado limitado a unos pocos cultivos tradicionales como maíz, papa, trigo, arroz, yuca y algunas leguminosas como frijol, lenteja, quinua. En este trabajo tiene como objetivo realizar una caracterización y evaluación de las propiedades físico-químicas, funcionales y estructurales del almidón y harina extraídos a partir del fruto del Chachafruto.

\section{MATERIALES Y MÉTODOS}

El chachafruto fue recolectado en la zona cafetera de Colombia, de acuerdo con los criterios del productor como tamaño, color y estado fitosanitario de las vainas y fue transportado refrigerado al laboratorio.

La harina de chachafruto se obtuvo separando las semillas de la vaina, luego se cortaron en rodajas y se secaron en estufa a $45^{\circ} \mathrm{C}$; 48 horas, posteriormente se molieron y se tamizaron; la harina se almacenó en bolsas plásticas selladas para análisis posteriores (Dufour et al. 2009).

Extracción de almidón. La materia prima cortada en rodajas; se licuó con agua destilada por 1 minuto a baja velocidad, el homogenizado se pasó a través de una malla de $54 \mu \mathrm{m}$, con adición de agua destilada hasta que el agua de lavado estuviera completamente limpia; a continuación el filtrado se centrifugó a 10.800 g durante 10 minutos. El sedimento correspondiente al almidón se secó en un horno de convección a $40^{\circ} \mathrm{C}$ por $24 \mathrm{~h}$, para posteriormente almacenarlo a $12^{\circ} \mathrm{C}$ y $92 \%$ de humedad en refrigeración.

Para la harina y el almidón de Chachafruto se estudiaron, la proteína cruda (Método 46-13, AACC 2000), humedad (método 925.10, AOAC 2000), extracto seco total (Método 30-25, AACC 2000), cenizas (Método 08-01, AACC 2000), fibra dietética insoluble, fibra dietética soluble y fibra dietética total (método 992.16, AOAC 2000). Todas las mediciones se llevaron a cabo por triplicado.

El contenido de calcio de la harina de chachafruto se determinó por el procedimiento de incineración en seco 968,08 (AOAC 2000). La concentración de minerales se midió con un espectrómetro de absorción atómica de doble haz (Perkin Elmer 300) equipado con una lámpara de deuterio, corrector de fondo y una lámpara de cátodo hueco. El equipo fue operado con 12 psi de aire seco, 70 psi de acetileno, una Ilama de 422,7 nm, una lámpara de 65 mA de corriente, y una anchura de la rendija 0,7 nm. El fósforo en la harina de chachafruto se determinó según el método oficial AOAC 965.17.

Determinación de temperatura y entalpia de gelatinización $\left(T_{p}\right.$ y $\left.\Delta H_{p}\right)$. Se llevo a 
cabo por medio de un Calorímetro Diferencial de Barrido (TA Instruments DSC-Q100), en muestras de $(10 \pm 0,5) \mathrm{mg}$ con un contenido de humedad del $80 \%$, para una velocidad de $5{ }^{\circ} \mathrm{C} / \mathrm{min}$, desde temperatura ambiente hasta $100^{\circ} \mathrm{C}$, en atmosfera de nitrógeno y en charolas herméticamente selladas. La descomposición térmica de las harinas y almidones se estudió a través de la técnica de análisis termogravimétrico (TA Instruments TGA Q500), realizando los experimentos en presencia de una atmosfera de nitrógeno para un rango temperaturas desde ambiente hasta $800^{\circ} \mathrm{C}$ a $5^{\circ} \mathrm{C} / \mathrm{min}$ y en muestras de $(6 \pm 0,5) m g$ (Pineda, Coral y Ramos 2011).

El análisis de la morfología de los gránulos de almidón de chachafruto se realizó en un microscopio electrónico de barrido (SEM) a bajo vacio (LV-SEM, JSM 5600LV), con resolución de $5 \mathrm{~nm}$ en el modo LV, acoplado con un espectrómetro de dispersión de energía de rayos X (Noran model Voyager 4.2.3). Antes del análisis, las muestras fueron pulidas con diferentes tipos de papel lija (Fandeli SIC A-99-600, 1200). Este tratamiento garantiza que la estructura observada no se vea afectada por el corte de la máquina (Londoño 2014).

Después de este procedimiento, las muestras fueron desempolvadas con aire para remover el papel lija y el exceso de materiales orgánicos. Estas muestras no son materiales conductores, sin embargo fue necesario recubrir la muestra con una capa de oro. Las muestras fueron fijadas sobre el portamuestras de cobre con una tapa de carbono. Las condiciones de análisis usadas para la obtención de las imágenes sobre diferentes superficies con la señal electrónica retrodispersa fueron: voltaje de $15 \mathrm{kV}$, una presión de 12 a 20 Pa en el portamuestras. El análisis fue hecho en cortes internos y transversales.

Para la caracterización con difracción de rayos $X$, las muestras del almidón nativo del fruto $y$ de la harina fueron reducidas a un polvo fino y pasados a través de una malla de $150 \mu \mathrm{m}$ de tamaño de poro. Las muestras en polvo fueron empacados densamente dentro de una montura de aluminio. Los patrones de difracción de rayos $X$ se obtuvieron usando un equipo Siemens D5000, con una línea de radiación Cu Ka $(l=1.5418 \AA$ ̊), con una diferencia de potencial de $30 \mathrm{kV}$ y una densidad de corriente de $20 \mathrm{~mA}$. Las muestras se registraron entre 5 y 40 grados $(2 q)$ con un paso angular de 0,050 y un tiempo de conteo por paso angular de 15 segundos. El material se colocó en un portamuestra de aluminio de área de $30 \mathrm{~mm}$ por $30 \mathrm{~mm}$ a temperatura ambiente $y$ baja humedad (Nimsung, Thongngam y Naivikul 2007).

Las propiedades funcionales de las harinas y almidones, se realizaron utilizando un analizador rápido de viscosidad RVA-4 (Viscoamilograma RVA Rapid Visco Analyser, Newport Scientific Narabeen, NSW, Australia), con perfil definido de temperatura (50 hasta $90^{\circ} \mathrm{C}$ a $6^{\circ} \mathrm{C} / \mathrm{min}$., para mantener la temperatura durante 5 minutos y luego enfriar hasta $50^{\circ} \mathrm{C}$ a $6^{\circ} \mathrm{C} / \mathrm{min}$.). Para las harinas se utilizó una suspensión al 8\% (b.s.) en presencia de inhibidor de $\alpha$-amilasa $\left(\mathrm{AgNO}_{3}\right.$; $0,002 \mathrm{~mol} / \mathrm{L}$ ) y los almidones solo con el volumen de agua respectivo y una concentración del 7\%. Además, se determinó el tiempo y la temperatura de inicio de empastamiento (temp y Temp), la viscosidad máxima (Vmax), el tiempo para llegar al pico máximo (tVmax), la temperatura en el pico maximo (TVmax), la viscosidad de la pasta caliente (después de 5 minutos a $90^{\circ} \mathrm{C}$ ) (VPC), la viscosidad mínima (Viscosidad más baja después de $V \max (V \min )$, la viscosidad de 
la pasta después del enfriamiento a $50^{\circ} \mathrm{C}(\mathrm{VPE})$; Viscosidad final (Vfin). Con base a estos datos se estimaron 4 parámetros: Facilidad de cocción (FC) estimado como (tVmax - temp); breakdown (BD), calculado como (Vmax - VPC); setback (SB), calculado como (VPE- Vmax); consistencia (CS), calculado como (VPE - VPC) (Dufour et al. 2009).

\section{RESULTADOS Y DISCUSIÓN}

Al analizar los resultados químicos obtenidos por el análisis proximal para la harina de chachafruto, se observan altos contenidos de proteína y almidón equivalentes al 18,5\% y $13,1 \%$ respectivamente (Tabla 1). Estos resultados se establecen como altos, porque los datos obtenidos por otros autores para almidones de maíz, guineo y mafafa muestran valores entre 7,1 y $11 \%$ de proteína y de legumbres entre 23,5 y 25,8 \% (Jamroz 2009; Lucas 2013; Londono 2014; Young y Pellett 1994).

\section{Análisis fisicos.}

En la figura 1, se muestran las fotomicrografías de los gránulos de almidón con superficie lisa, sin fracturas ni roturas, además se observa una matriz proteica que envuelven los gránulos de almidón en forma de una red cristalina en los cortes longitudinal de la semilla de chachafruto. Igualmente se evidencia la ruptura de los sacos proteicos que envuelven los gránulos de almidón en el momento en que se hace el corte transversal.

Los gránulos de almidón de chachafruto presentaron tamaños variables donde se encuentran diámetros longitudinales que van desde $10 \mathrm{~m}$ hasta $18,3 \mathrm{~m}$ y transversales que van desde $11 \mathrm{~m}$ hasta $22,3 \mathrm{~m}$; con formas ovaladas y semiesféricas. Además, se observan grupos de gránulos de proteína con dimensiones promedio de 4,54 m, agrupados a los costados de los gránulos de almidón, presentando estructuras variables entre las que se encuentran algunas poliédricas. Estudio realizados por Londono-Restrepo et al. (2014) demostraron que el almidon de mafafa tiene dimesiones un poco menores al almidon de chachafruto, reportando diametros de 7 a 11 m y otros autores Jamroz (2009) reportaron diámetros para el almidón de papa y de maíz de 6,45 y $8,81 \mathrm{~nm}$.

Tabla 1. Caracterización química de la harina y el almidón de chachafruto.

\begin{tabular}{lcc}
\hline \multicolumn{1}{c}{ Análisis } & Harina de chachafruto (\%) & Almidón de chachafruto (\%) \\
\hline Humedad & 12,50 & 12,60 \\
Cenizas & 1,5 & 0,90 \\
Proteína & 18,50 & 0,80 \\
Grasas & 2,50 & 1,82 \\
Fibra & 0,50 & $\mathrm{ND}$ \\
Almidón $(\%)$ & 13,10 & $\mathrm{ND}$ \\
Fósforo $\mathrm{mg} / 100 \mathrm{~g}$ & 81,00 & $\mathrm{ND}$ \\
Hierro $(\mathrm{mg} / \mathrm{mL})$ & 0,98 & $\mathrm{ND}$ \\
Calcio $\mathrm{mg} / \mathrm{100g}$ & 13,00 & $\mathrm{ND}$ \\
Vitamina A mg/100g & 0 & $\mathrm{ND}$ \\
Vitamina C mg/100g & 7,80 & \\
\hline
\end{tabular}

ND: No determinado 
La morfología de los gránulos de almidón puede ser atribuida al origen botánico, a la morfología de los amiloplastos, el grado de maduración del fruto y la fisiología de la planta. Delpeuch y Favier (1980) indican que el tamaño del granulo de almidón tiene una influencia sobre las propiedades funcionales, mientras más pequeños sean los gránulos, mayor es su digestibilidad y son considerados como los más resistentes a procesos con altas temperaturas como la esterilización. En algunos almidones, el tamaño de los gránulos de almidón muestra relación con su proporción
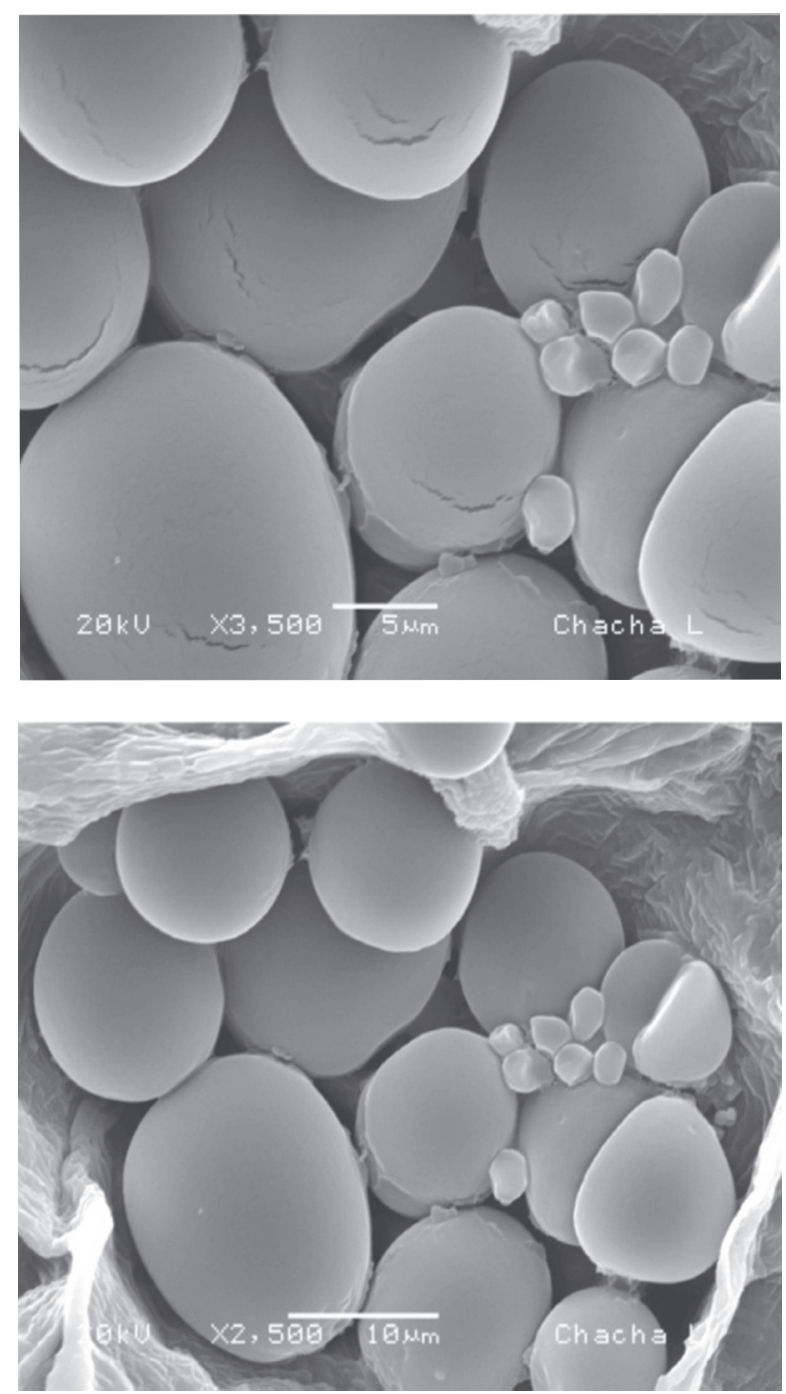

Figura 1. Fotografías de microscopia electrónica de barrido del almidón de chachafruto. solo uno de sus extremos. a $17 \mu \mathrm{m}$.

amilosa/amilopectina (Pacheco 2009). La forma general del granulo de almidón de chachafruto se aproxima a elipses y/o esferas, en ocasiones truncadas, como si hubiese recibido cortes en direcciones aleatorias en

Mediante el análisis con microscopia electrónica de barrido SEM, se observa una distribución de los gránulos de almidón, donde aproximadamente el $7,14 \%$ de los gránulos presentan tamaños entre 11 - $14 \mu \mathrm{m} ; 57,14 \%$ de gránulos tienen tamaños entre 14 y $17 \mu \mathrm{m}$ y el $35,71 \%$ restantes, presentan tamaños mayores
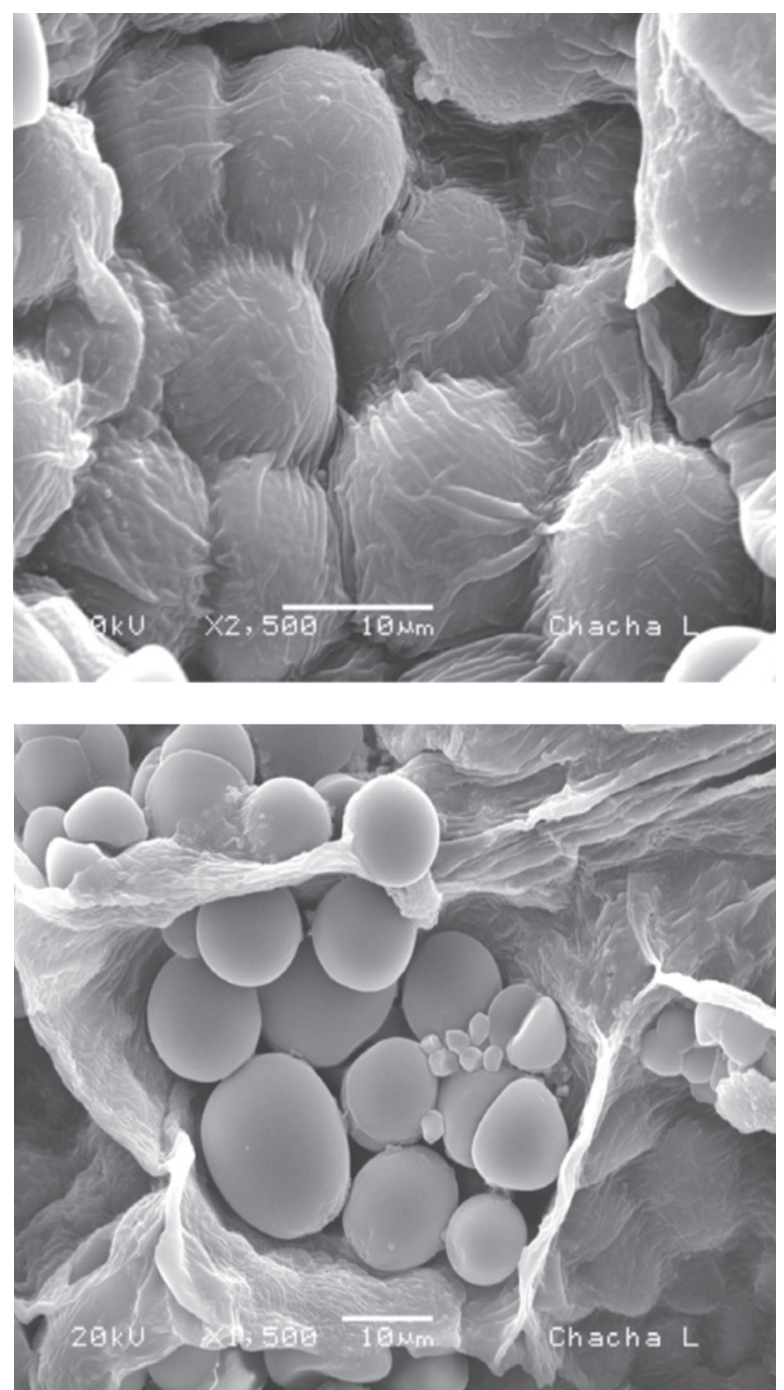
Quintero et al. - Determinación de propiedades del Chachafruto

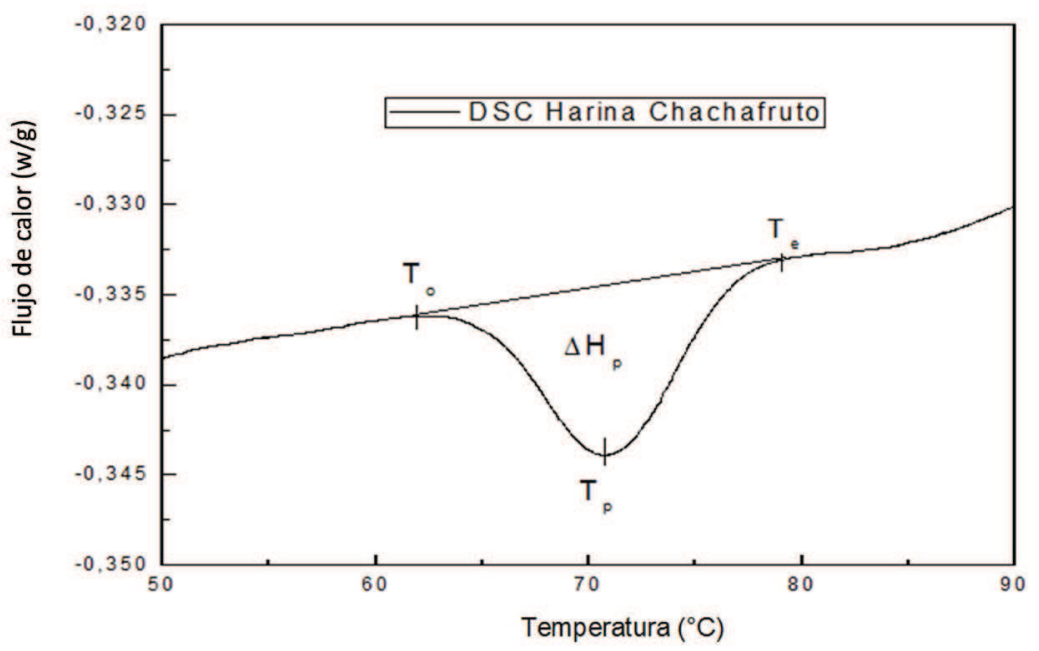

Figura 2. Termograma DSC para harina de chachafruto.

En la figura 2, se muestra el termograma DSC y datos arrojados de la harina de chachafruto, donde se presenta la transición térmica de gelatinización, comenzando con un suave pico endotérmico sobre la línea base del termograma. El proceso, aquí representado, empieza a $61,95^{\circ} \mathrm{C}$, esta temperatura se conoce como temperatura inicial (To). La temperatura de pico (Tp) que es la temperatura donde se registran los valores más altos de absorción de calor para la harina de chachafruto fue encontrada a los $70,7^{\circ} \mathrm{C}$ y la temperatura de finalización (Te) de la gelatinización con $79,1^{\circ} \mathrm{C}$ que se presenta a medida que el proceso finaliza.

La energía necesaria para completar el proceso se conoce como entalpía de gelatinización, que se calcula como el área bajo la curva del pico de gelatinización, $(\Delta \mathrm{Hp})$ y para la harina de chachafruto su valor es de 0,814 J/g; donde además se analizan los cambios estructurales y químicos que influirán en la calidad de los productos que se derivan de esta materia prima (Nimsung, Thongngam y Naivikul 2007).

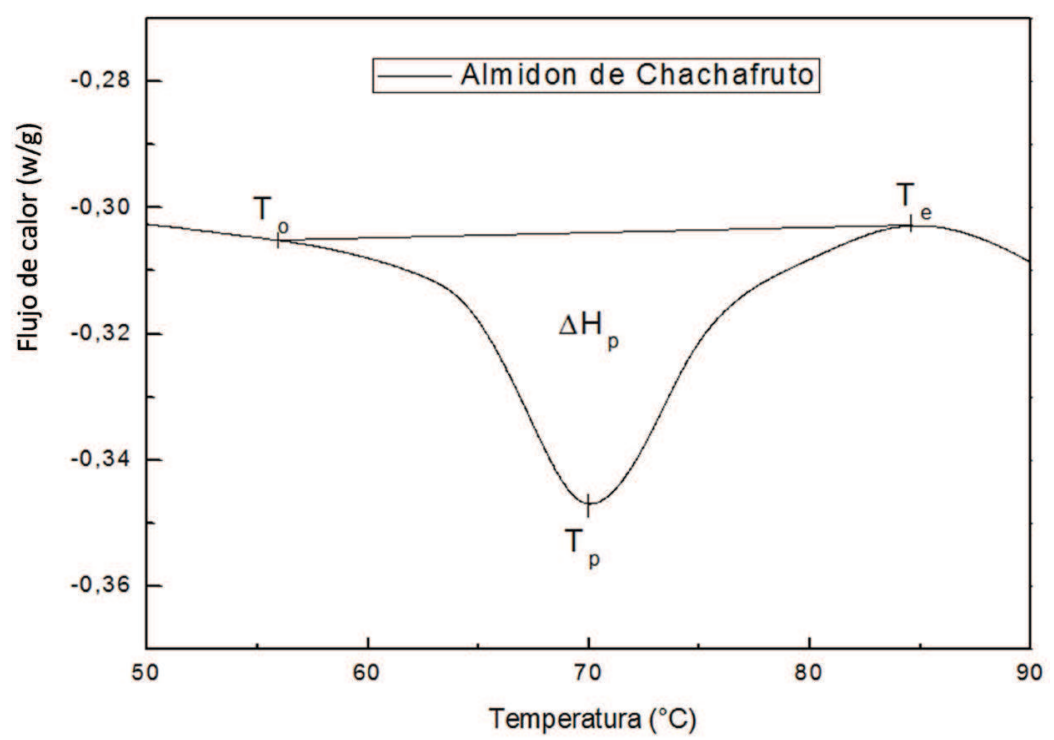

Figura 3. Termograma DSC para almidón de chachafruto. 
En los gránulos de almidón de chachafruto (Figura 3), es evidente la presencia de una transición endotérmica entre los $55,85^{\circ} \mathrm{C}$ y $84,66^{\circ} \mathrm{C}$, que es característico de la transición endotérmica de almidón. La entalpía de este proceso fue $4,86 \mathrm{~J} / \mathrm{g}$, que es un indicativo de almidón con orden cristalino.

A esta temperatura, los polímeros con bajo peso molecular, particularmente las moléculas de la amilosa, empiezan a separarse del gránulo del almidón. Conforme la temperatura aumenta, los gránulos del almidón comienzan a colapsar hasta que finalmente la parte amorfa (Amilosa) queda totalmente solubilizada, mientras que la parte cristalina del almidón se mantiene en la solución acuosa (Coral 2007).
La Figura 4, muestra el termograma TGA (Línea continua) de la curva de degradación térmica y su primera derivada (Línea punteada) para La Figura 4, muestra el termograma TGA (Línea continua) de la curva de degradación térmica y su primera derivada (Línea punteada) para la harina de chachafruto, donde se observan tres regiones diferentes relacionadas con las pérdidas de masa más pronunciadas.

La zona uno corresponde a la pérdida de masa representada por la humedad presente en la muestra, donde la cantidad de agua disponible fue de $7,84 \%$. Esta disminución se presentó entre los 25 y $121,6^{\circ} \mathrm{C}$ presentando su mayor pico alrededor de los $119,79^{\circ} \mathrm{C}$ (Tabla 2).

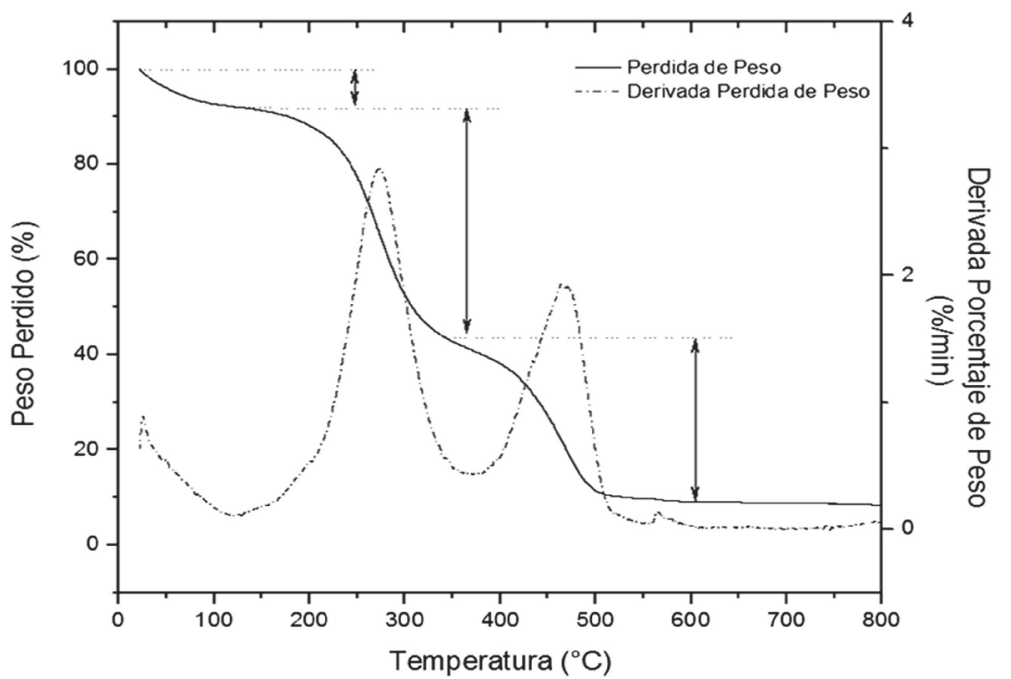

Figura 4. Termograma (TGA) para harina de Chachafruto.

Tabla 2. Temperaturas de descomposición térmica de la harina y almidones de chachafruto.

\begin{tabular}{|c|c|c|c|c|c|}
\hline Producto & $\begin{array}{r}\begin{array}{r}\text { Eventos } \\
\text { térmicos }\end{array} \\
\text { Primero }\end{array}$ & \multicolumn{2}{|c|}{ Rango $\left({ }^{\circ} \mathrm{C}\right)$} & $\begin{array}{c}\begin{array}{c}\text { Porcentaje } \\
\text { de peso }(\%)\end{array} \\
7,84\end{array}$ & $\begin{array}{c}\text { Temperatura de pico } \\
\text { en derivada }\left({ }^{\circ} \mathrm{C}\right)\end{array}$ \\
\hline Harina & $\begin{array}{r}\text { Primero } \\
\text { Segundo } \\
\text { Tercero } \\
\text { Residuo }\end{array}$ & $\begin{array}{r}25,00 \\
121,06 \\
371,58\end{array}$ & $\begin{array}{ll}- & 121,06 \\
- & 371,58 \\
- & 544,83\end{array}$ & $\begin{array}{r}7,84 \\
50,88 \\
32,10 \\
8,30\end{array}$ & $\begin{array}{l}119,79 \\
273,17 \\
466,80\end{array}$ \\
\hline Almidón & $\begin{array}{c}\text { Primero } \\
\text { Segundo } \\
\text { Tercero } \\
\text { Residuo }\end{array}$ & $\begin{array}{r}50,00 \\
246,00 \\
373,82\end{array}$ & $\begin{array}{l}-\quad 250,00 \\
-\quad 364,00 \\
-\quad 584,72\end{array}$ & $\begin{array}{r}10,92 \\
68,52 \\
19,41 \\
1,15\end{array}$ & $\begin{array}{l}200,94 \\
301,21 \\
493,40\end{array}$ \\
\hline
\end{tabular}


Lapérdidadepesomásrepresentativasepresentó en la zona 2 con rango de temperaturas entre $121,6^{\circ} \mathrm{C}$ y $371,58^{\circ} \mathrm{C}$, teniendo su pico máximo en $273,17^{\circ} \mathrm{C}$. Con esta información y basándose en la composición química de la muestra de harina de chachafruto, se considera que en este punto se descomponen carbohidratos y péptidos de bajo peso molecular. Esto puede incidir en la descomposición del almidón y las proteínas presentes en la muestras, ya que esta pérdida de peso fue del 50,88\%. Para este estudio es de gran importancia la zona 2 porque representa la mayor pérdida de masa de la muestra. Esta pérdida se presenta como una curva característica de descomposición simple o de un solo paso como se presenta en la gráfica.

En la zona 3, la harina mostro una pérdida de peso de $32,1 \%$ con un rango de temperaturas entre $371,42^{\circ} \mathrm{C}$ a $544,83^{\circ} \mathrm{C}$ con un pico máximo presentado en $466,8^{\circ} \mathrm{C}$. En esta zona se descomponen polisacáridos de alto peso molecular como proteínas, lípidos entre otros compuestos orgánicos, además el porcentaje de residuos presentados en el termograma son del $8,39 \%$, que es un alto valor, lo que indica que la harina de chachafruto contiene altas concentraciones de minerales que pueden ser sales acopladas.

En cuanto a los almidones de chachafruto la figura 5, muestran la curva de degradación térmica correspondiente a los experimentos dinámicos y su primera derivada, encontrándo tres regiones diferentes. En la I región, con la pérdida de masa de alrededor de 10,92\% característico de la pérdida del contenido de humedad de la muestra. La región II, con pérdida de masa de $68,52 \%$ en el intervalo de temperatura entre 246 a $364^{\circ} \mathrm{C}$ corresponde a la fase de descomposición pirolitica de los biopolímeros (amilosa y amilopectina) (Yaoqi Tiana 2011). Esta etapa de descomposición, presenta su máximo velocidad de reacción en $301,21^{\circ} \mathrm{C}$, como lo indica el pico en la curva derivada DTG (Línea punteada). Para la región III, es evidente la descomposición de un $19,41 \%$ de la masa, que se puede interpretar como una recombinación de los productos de combustión con sales inorgánicas. Los resultados TGA indican que el almidón de chachafruto es térmicamente estable a temperaturas inferiores a $246^{\circ} \mathrm{C}$ donde inicia el proceso de degradación térmica.

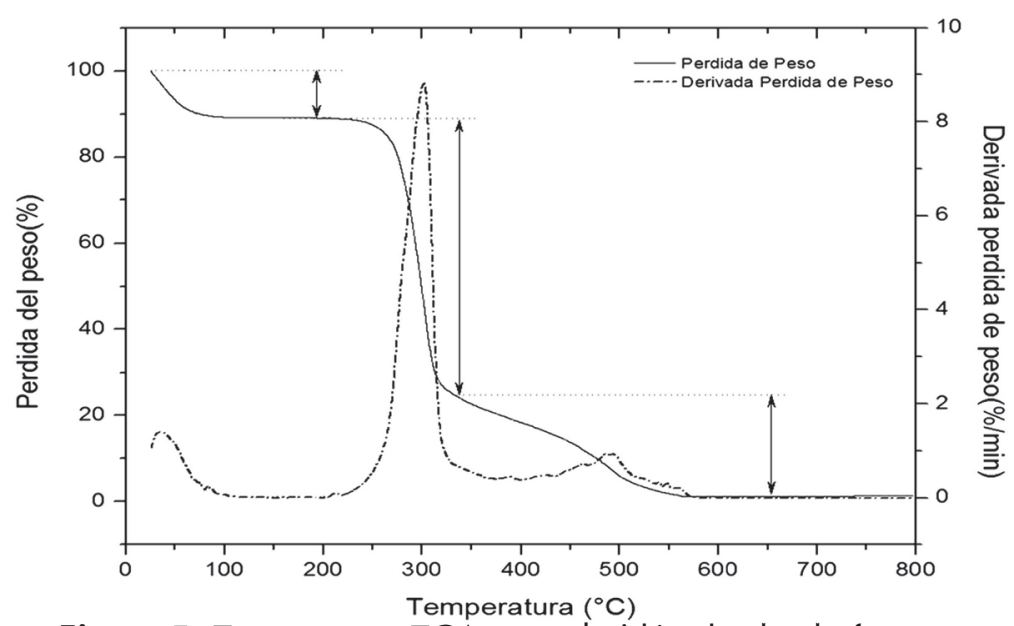

Figura 5. Termograma TGA para almidón de chachafruto. 
Los patrones de difracción de rayos $\mathrm{X}$ de la amilosa, la amilopectina y el almidón de chachafruto (Figura 6), indican que la amilopectina exhibe la mejor calidad de cristalinidad relativa, mientras que la amilosa constituye la fase menos cristalina del almidón. Claramente, las macromoléculas amilopectina en los gránulos de almidón tienen un mejor orden cristalino que es amilosa (Hermansson y Svegmark 1996; Jianhua Liu 2011).

Los gránulos de almidón nativos exhiben dos tipos principales de diagrama como se observa en la Figura 6. El tipo A para almidones de cereales y el tipo B para tubérculos y almidones ricos en amilosa. Otro tipo de diagrama de difracción es el C, el cual se muestra como una mezcla de diagramas A y $\mathrm{B}$, que es característico de la mayoría de almidones de legumbres y también de cereales que crecen en condiciones específicas de temperatura e hidratación. De acuerdo con datos de difracción de polvo de amilosa ( $\alpha$-amilosa 43-1858) (Imberty 1998), esta estructura no presenta los picos situados en $15,214(d=-5,8191 \AA) ; 21,154(d=3,8382 \AA)$ en la escala $2 \theta$ que son característicos para la identificación amilopectina (Rojas et al. 2007). El patrón de difracción del almidón de chachafruto analizado, podría considerarse como una mezcla de los tipos A y B (Figura 6), ya que el patrón $B$ presenta dos picos característicos $2 \theta=5^{\circ}$ y $2 \theta=18^{\circ}$, mientras que en este estudio sólo se encontró el segundo $2 \theta=18^{\circ} ;$ además, se encontraron picos característicos del patrón A, para el cual se han establecido los siguientes: $2 \theta=15,17,23^{\circ}$.

Como se ha mencionado, los gránulos de almidón son una mezcla de amilosa y amilopectina, por lo tanto, las variaciones

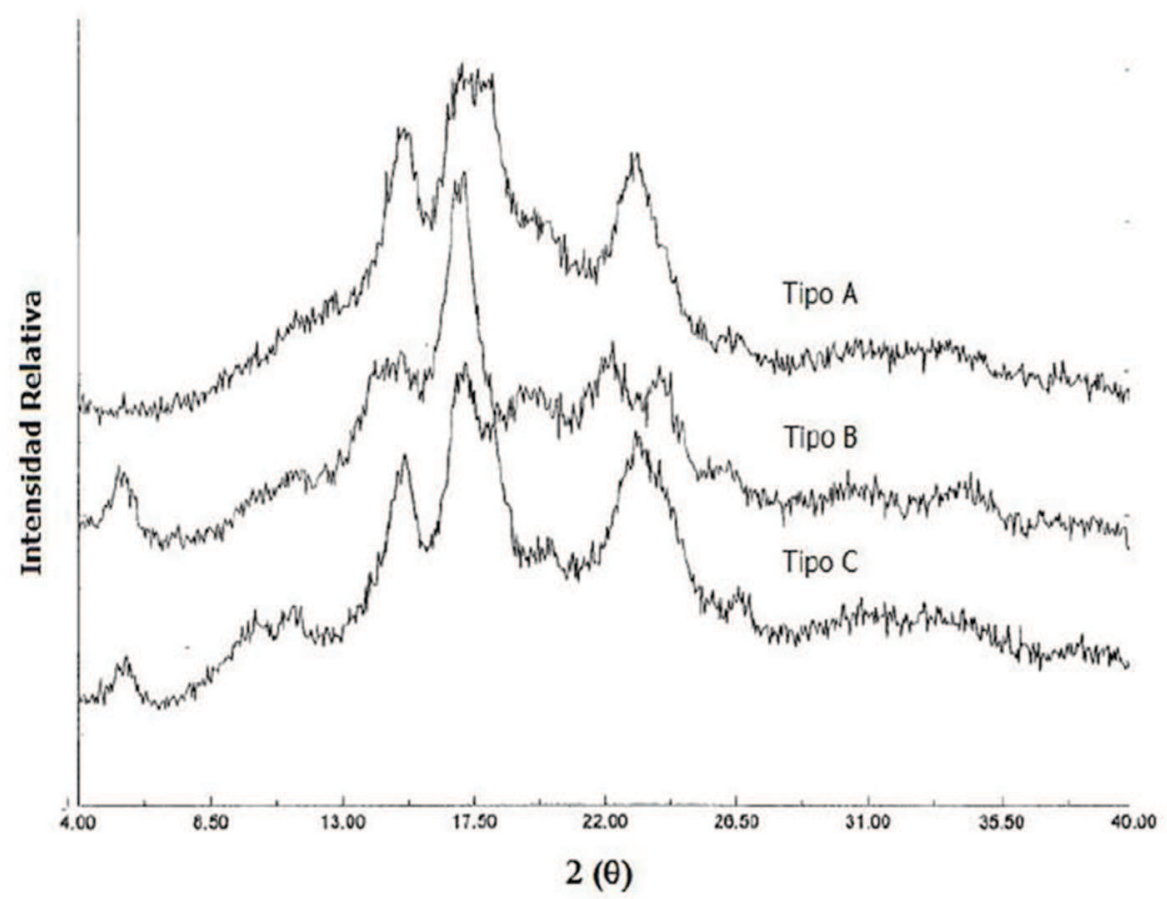

Figura 6. Patrones de difracción de rayos x para almidones. 
en la proporción de estos polisacáridos y sus propiedades e interacciones con otros componentes, pueden explicar las diferencias en el comportamiento del hinchamiento de los gránulos y la funcionalidad de los almidones de diferentes orígenes.

El comportamiento reológico en RVA, de las harinas y almidones de chachafruto, se muestran en la figura 7, donde se observa inicialmente que los almidones desarrollaron normalmente su viscosidad al someterlos al tratamiento hidrotérmico, mientras que en las harinas no se presentó este fenómeno, por lo que solo se analizaran los almidones.

El viscoamilograma permite evaluar la temperatura de inicio y el tiempo de inicio de gelatinización de los gránulos de almidón, en la cual se observa un inicio de incremento de la viscosidad, cuyos valores son $73,77^{\circ} \mathrm{C}$ y 4,99 minutos, respectivamente. Valores parecidos a los reportados en Musáceas con valores entre 74,7 y $76^{\circ} \mathrm{C}$ y $5,1-5,4 \mathrm{~min}$ (Lucas et al. 2010). Al necesitarse temperaturas más altas y mayores tiempos para que se inicie el proceso de gelatinización de los almidones, mayor es el consumo de energía para que los gránulos de almidón se comiencen a hinchar.

Al seguir analizando el viscoamilograma, en las variables viscosidad máxima (Vmax), tiempo (tVmax) y temperatura (TVmax) para llegar al pico máximo, los datos obtenidos fueron $2689 \mathrm{cP}, 89,9^{\circ} \mathrm{C}$, $8 \mathrm{~min}$. Se encontró que los almidones de chachafruto desarrollan viscosidades más altas, que incluso el almidón de yuca $(1553,7$ cP), almidón de papa dulce $(1593,6 c P)$, almidón de trigo $(399,6 c P)$ (Zaidul et al. 2007).

Entre más altos sean los valores de las variables tiempo (tVmax) y temperatura (TVmax) para llegar al pico máximo, se puede deducir que

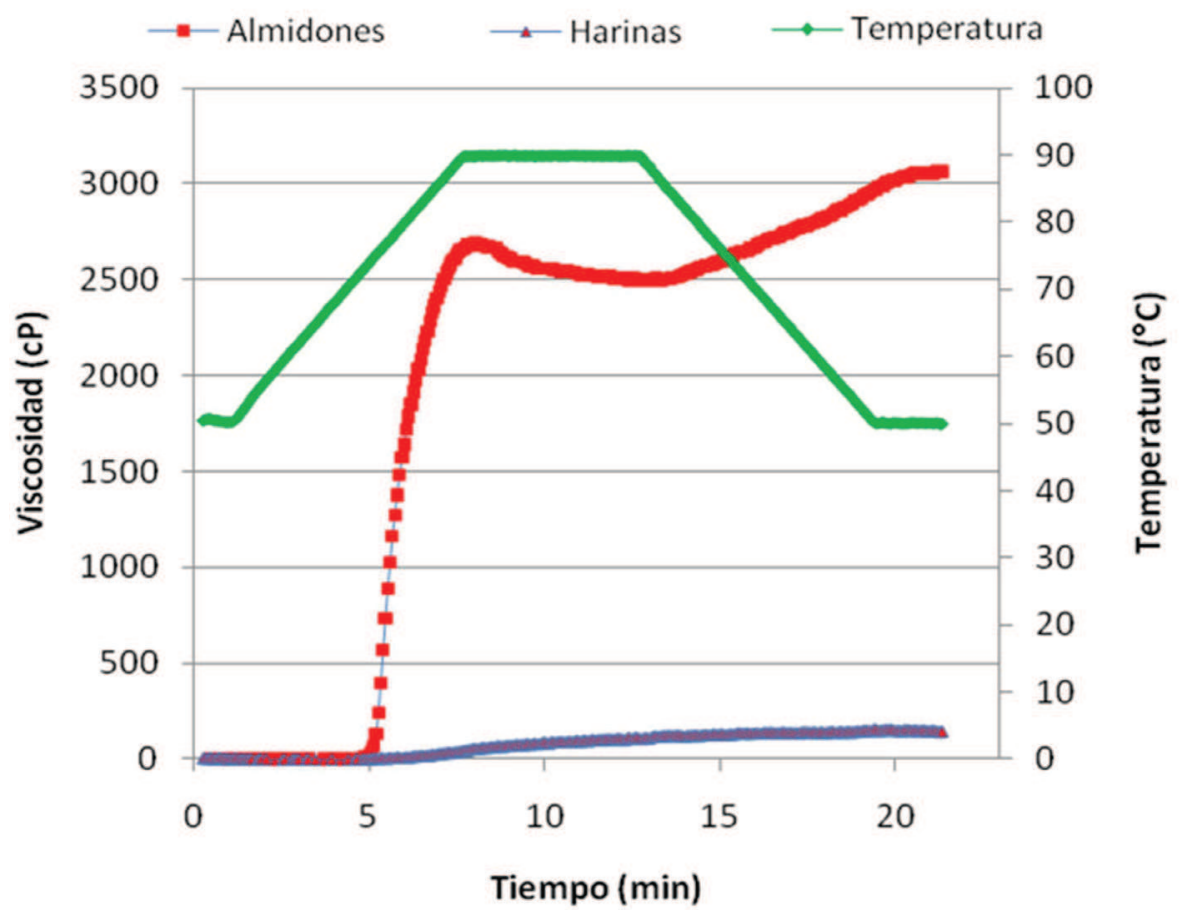

Figura 7. Perfiles viscoamilograficos de las harinas y almidones de chachafruto. 
los almidones se demoran mas en llegar al punto de viscosidad máxima, incidiendo directamente en la variable facilidad de cocción (FC) estimado como tVmax - temp, cuyo valor es de 3,01 min. Estos resultados indican que al demandar mayor tiempo, se necesita de más energía para alcanzar hinchamiento de todos los gránulos, desde el momento en que se inicia el proceso, obteniéndo datos muy parecidos a las musáceas que reportan valores entre 2,5 3,6min. (Lucas et al. 2010).

Al terminar el calentamiento durante las pruebas de RVA, con relación a la variable viscosidad de la pasta caliente (VPC) y durante el proceso de enfriamiento la viscosidad mínima (Vmin), los valores obtenidos equivalen a 2497 y $2495 c$, respectivamente. En la variable viscosidad de la pasta fría (VPE), la cual tiene que ver con la tendencia o habilidad de las suspensiones para formar una pasta viscosa o gel después de cocción o enfriamiento, el dato obtenido fue de $2957 \mathrm{cP}$.

La inestabilidad del gel (Breakdown: BD) (Figura 7), es un indicativo de que tan estables y resistentes al cizallamiento son los geles en procesos agroindustriales y representa la fragmentación de los gránulos, entre más bajo sea el valor muchos más estables son los geles a la fragmentación mecánica, lo que ocurre con los almidones de chachafruto con un valor de 192cP.

En la variable reorganización (Setback: SB), que define la reasociación de los polímeros de almidón solubles y los fragmentos granulares insolubles durante la fase de enfriamiento, se asocia a la retrogradación. Entre más alto el valor, los almidones son más susceptibles de sufrir retrogradación, lo que no ocurre con el chachafruto con valores de $268 \mathrm{cP}$, además en la variable consistencia (CS), el valor arrojado es de 460 cP.

En general las viscosidades más altas en cada una de las variables dependientes como viscosidad máxima (Vmax), Viscosidad de la pasta caliente (VPC), Viscosidad mínima (Vmin), Viscosidad de la pasta fría (VPE), son mayores en el almidón de chachafruto, que en las musáceas (Lucas et al. 2010), lo cual da un indicio del uso potencial al que se destinaría como es la elaboración de las sopas por la facilidad de cocción y la alta viscosidad preferida por los consumidores.

Además de los bajos valores obtenidos en las variables estabilidad a la fragmentación mecánica y su resistencia a la retrogradación y consistencia, también podrían ser evaluadas en la elaboración de productos que requieran de altas temperaturas para su procesamiento como alimentos enlatados, alimentos para niños, salsas, productos de panificación, jaleas, caramelos y embutidos cárnicos; pero no es viable utilizarlos en productos que se almacenen a condiciones de refrigeración y congelación.

Con respecto al comportamiento de las harinas en el análisis reológico, en la figura 7 , se observa que estás no desarrollan viscosidad durante el tratamiento hidrotérmico, entre una de las posibles causas está el alto contenido de taninos, que son comunes encontrarlos en frutas (Uva, caqui, arándanos), en el té, el chocolate, en los forrajes y árboles de leguminosas y en pastos. Los taninos son polifenoles naturales de la planta, estos pueden tener una gran influencia sobre el valor 
nutritivo de muchos alimentos consumidos por los seres humanos. Se componen de un grupo muy diverso de oligómeros y polímeros y su principal característica es que pueden formar complejos con proteínas, almidón, celulosa y minerales produciendo así la formación de complejos insolubles repercutiendo esto en la imposibilidad de generar viscosidad por parte del almidón en los tratamientos térmicos a los cuales se puede someter la harina de chachafruto.

Los taninos, no sólo se unen y precipitan las proteínas, sino que se encuentran principalmente en las vacuolas o cera de la superficie de las plantas. En estos sitios que no interfieran con el metabolismo de la planta. Sólo después de descomposición y muerte celular pueden actuar y tener efectos metabólicos.

\section{CONCLUSIONES}

El análisis realizado para determinar el porcentaje de minerales contenidos en la harina de chachafruto se establecieron cantidades para fosforo, hierro y calcio de 81; 0,98 y $13 \mathrm{mg} / 100 \mathrm{~g}$ respectivamente.

Con la ayuda de la técnica microscópica SEM se concluye que el almidón evaluado es un almidón nativo sin ningún grado de gelatinización, revelando de esta manera que sus propiedades funcionales no han sido alteradas durante el proceso de extracción el cual se puede afirmar que fue eficiente por la ausencia de impurezas.

El análisis termogravimétrico para harina de chachafruto encontró que el proceso inició a $26,25^{\circ} \mathrm{C}$, la perdida de humedad se presentó a una temperatura de $119,99^{\circ} \mathrm{C}$, la temperatura máxima de descomposición a los $272,5^{\circ} \mathrm{C}$ y el proceso termina en $581^{\circ} \mathrm{C}$.

Para el almidón de chachafruto se demostró que el inicio de descomposición fue a $25^{\circ} \mathrm{C}$, la descomposición del agua disponible se presentó a $200,94^{\circ} \mathrm{C}$, la temperatura máxima de descomposición se observó a los $300^{\circ} \mathrm{C}$ y el proceso finalizó a $584,72^{\circ} \mathrm{C}$.

Al realizar el análisis por medio de calorimetría diferencial de barrido DSC para harina se encontró que las temperaturas características para el proceso de gelatinización son $\mathrm{TO}=$ $62,06^{\circ} \mathrm{C}, \mathrm{TP}=70,98^{\circ} \mathrm{C}, \mathrm{TF}=78,62^{\circ} \mathrm{C}$ y una entalpia de gelatinización $\Delta \mathrm{Hp}=0,8144 \mathrm{~J} / \mathrm{g}$.

Del termograma DSC para almidón de chachafruto se obtuvo que $\mathrm{TO}=56,65^{\circ} \mathrm{C}$, $\mathrm{TP}=70,06 \%, \mathrm{TF}=85,12^{\circ} \mathrm{C}$ y una entalpia de gelatinización $\Delta \mathrm{Hp}=4,866 \mathrm{~J} / \mathrm{g}$.

\section{REFERENCIAS}

AACC International. 2000. Approved Methods of American Association of Cereal Chemists, 10th Ed. Method 08-01, Method 30-25 and Method 46-13. The Association: St. Paul, MN.

AOAC. 1998. Official Methods of Analysis. 16th ed. Maryland USA, Official Method 968.08: Association of Official Analytical Chemists.

AOAC. 2000. Official Methods of Analysis of the Association of Official Analytical Chemists, 
17th Ed. Method 925.10, 920.86, 992.16 and 965.17. The Association: Gaithersburg, MD. USA.

Biliaderis, C. 1992. Structures and Phase Transitions of Starch in Food Systems. Food Technology, 145.

Coral, D. 2007. Caracterización térmica de biopolímeros derivados del maíz: almidón. Universidad Nacional de Colombia.

Delpeuch, F. y Favier, J. 1980. Caracteristique des amidons de plantas alimentaires tropicales: action de I'alpha-amylase, gonflement et solubilité. Paris, Ann. Technol. Agric., 29(1): 53-67.

Dufour, D., Gibert, O., Giraldo, A., Sanchez, T., Reynes, M., Pain, J., González, A., Fernández, A. and Díaz, A. (2009). Differentiation between cooking bananas and dessert Bananas. 2. Thermal and functional characterization of cultivated colombian Musaceae (Musa sp.). Journal of Agriculture and Food Chemistry. 209-216.

Dufour, D., Gibert, O., Giraldo, A., Sánchez, T, Reynes, M., Pain, J. P., González, A., Fernández, A. and Díaz, A. 2009. Differentiation between cooking bananas and dessert Bananas. 2. Thermal and functional characterization of cultivated colombian Musaceae (Musa sp.). Journal of Agriculture and Food Chemistry. 53-68.

Hermansson, A. and Svegmark K. 1996. Developments in the understanding of starch functionality. Trends in Food Science \& Technology, Vol. 71. 29-38
Jamroz, J and Sujka M. 2009. $\alpha$-Amylolysis of native potato and corn starches - SEM, AFM, nitrogen and iodine sorption investigations.» LWT - Food Science and Technology, 1219 1224.

Jianhua L., Bin W. and Jianyou Z. 2011. Functional, physicochemical properties and structure of cross-linked oxidized maize starch. Food Hydrocolloids, 413- 425.

Lucas, J. and Quintero, V. 2013. Caracterización de harina y almidón obtenidos a partir de plátano guineo AAAea (Musa sapientum L.).» ACTA Agronómica: 83 - 96.

Latham, M. 2002. Nutrición humana en el mundo en desarrollo. Organización de las Naciones Unidas para la Agricultura y la Alimentación. Colección FAO: Alimentación y nutrición N²29. Roma.

Lucas, A., Dufour, D. y Díaz, A. 2010. Caracterización físico - química y evaluación de las curvas de empastamiento de tres variedades de plátano: Hartón (Musa AAB), Cubano blanco (Musa AAB), Cachaco (Musa ABB). ACORBAT, Medellín - Colombia.

Nimsung, P., Thongngam, $\mathrm{M}$ and Naivikul, O. 2007. Compositions, morphological and thermal properties of green banana flour and starch. Kasetsart , 127-134.

Pacheco, E. y Techeira, N. 2009. Propiedades químicas y funcionales del almidón nativo y modificado de ñame. Interciencia, 38-50.

Pineda, P., Coral, D and Ramos, D. 2011. Thermo-alkaline treatment. A process that changes the thermal properties of corn starch.» 
Procedia Food Science, 370-378.

Rojas, I., Gutiérrez, E., Palacios, A., Baños, L., Pons, J., Guzmán, S., Pineda, P. and Rodríguez, M. 2007. Study of structural and thermal changes in endosperm of quality protein maize during traditional nixtamalization process. Cereal Chem. 84 (4), 304-312.

Ruskin, F. 1989. Basul. In Lost crops of the Incas. Washington, DC: National Academy Press, pp. 164-71.

Londoño, S., Rincón, N., Contreras, M., Acosta, A., Bello, L., Lucas, J., Dumar, V., Pineda, P., Del Real. A. and Rodríguez, $M$. 2014. Physicochemical, morpholoical, and rheological characterization of Xanthosoma robustum Lego-like starch. International Journal of Biological Macromolecules,: 222-228.

Jyothirmayi, T. y Prabhakara P. 2006. Nitrogen extractability and functional properties. Food Chemistry: 242-247.
Vega, D., Villar, M., Failla, M. and Valles, E. 1996. Polymer Bulletin 37, 229-235.

Yaoqi T., Yin L., Xueming X. and Zhengyu J. 2011. Starch retrogradation studied by thermogravimetric analysis (TGA).» Carbohydrate Polymers, 1165-1168.

Young, V. and Pellet, P. 1994. Plant proteins in relation to human protein and amino acid nutrition. Am. J. Clin. Nutr., 59 (Suppl.): 1203S-1212S.

Zaidul, I., Norulaini, N., Mohd. O., Yamauchi, H. y Noda, T. 2007. RVA analysis of mixtures of wheat flour and potato, sweet potato, yam, and cassava starches. Carbohydrate Polymers 69: 784-791. 